Digilec 8 (2021), pp. 137-150

Fecha de recepción: 23/02/2021

Fecha de aceptación: 27/04/2021

DOI: https://doi.org/10.17979/digilec.2021.8.0.7555
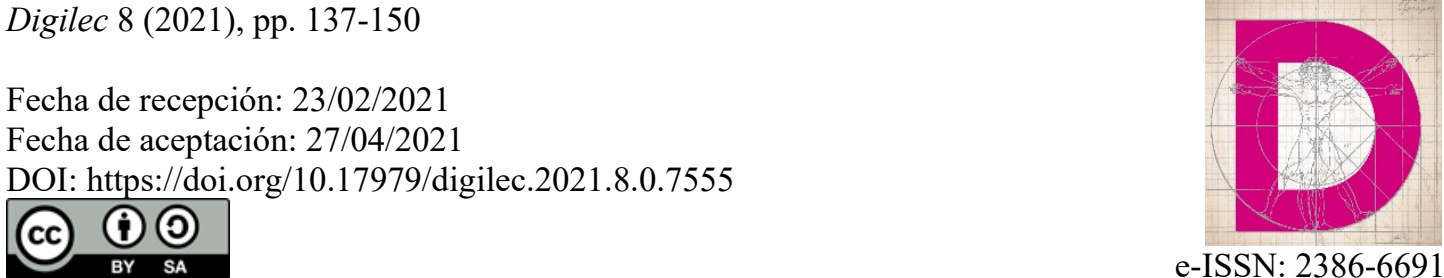

\title{
UNHA ACHEGA Á APRENDIZAXE DA LINGUA ITALIANA POLO ESTUDANTADO UNIVERSITARIO GALEGO DE NIVEL BÁSICO
}

\author{
A CONTRIBUTION TO LEARNING ITALIAN LANGUAGE BY BASIC \\ LEVEL GALICIAN UNIVERSITY STUDENTS
}

\author{
Emiliana TUCCI* \\ Universidade da Coruña \\ Orcid: https://orcid.org/0000-0002-0127-6215 \\ Cilha LOURENÇO-MÓDIA* \\ Universidade da Coruña \\ Orcid: https://orcid.org/0000-0003-0577-5852
}

\section{Resumo}

Unha das transformacións capitais producidas nas titulacións universitarias de ámbito lingüístico a partir da implantación da reforma de Boloña ten sido a introdución do enfoque comunicativo no ensino-aprendizaxe das linguas. Esta nova perspectiva ten achegado unha visión máis ampla e menos teórica do fenómeno lingüístico, mais, como consecuencia do maior protagonismo do enfoque comunicativo, tense producido certa desatención ao aspecto da corrección nos planos da Morfosintaxe, do Léxico e da Semántica; isto provoca que o estudantado se depare con dificultades gramaticais que nos plans de estudo anteriores se superaban con maior facilidade.

No sistema universitario galego esta situación reflíctese de maneira diversa dependendo de cal for a lingua primeira dos/das alumnos/as; o estudantado español-falante ten maiores problemas que o galego-falante na adquisición dos fundamentos gramaticais do italiano, a pesar de que na oralidade o idioma galego está hoxe bastante españolizado.

Así, este artigo ten como obxectivo sistematizar as vantaxes e os obstáculos que encontra o estudantado galego a fin de facilitar o traballo de docentes e discentes da lingua italiana no contexto universitario de Galiza. Por unha parte, desvendaranse as dificultades morfosintácticas e léxico-semánticas máis habituais -derivadas, as máis das veces, da interferencia co español- que o alumnado universitario galego encara nos primeiros momentos da aprendizaxe do idioma italiano; e, por outra banda, poranse de manifesto os aspectos comúns dos idiomas galego e italiano, que facilitan a adquisición deste último por funcionar o primeiro como interlingua.

\footnotetext{
* Universidade da Coruña. Facultade de Filoloxía. Departamento de Letras. Campus da Zapateira, Rúa Lisboa 7, 15008 A Coruña. Email: emiliana.tucci@udc.gal, cilla.lourenzo.modia@udc.gal.
} 
Palabras clave: italiano e galego; italiano e español; gramática contrastiva; competencia lingüística; italiano como lingua estranxeira: interlingua

\begin{abstract}
One of the most important transformations that has taken place in the field of linguistics since the establishment of the Bologna Reform, is the introduction of the communicative standpoint in language teaching and learning. This new perspective adds a wider and less theoretical vision of the linguistic approach, but, as a consequence of the greater role of the communicative standpoint, there is a certain inattention on the correctness aspect from the morphosyntax, lexical and semantic point of view; therefore, students have some grammatical problems that they would have solved easier in the old curriculum.

In the Galician university system this situation is reflected in a different way depending on the first language of the students; Spanish-speaking students find more problems than Galician-speaking students in the acquisition of Italian grammatical basics, in spite of the fact that in oral expression Galician is mostly influenced by Spanish nowadays.

The aim of this article is to systematize advantages and obstacles that Galician students find in order to facilitate the work of Italian teachers and students in university degrees in Galicia. On the one hand, we will analyse the most usual morphosyntax and lexicalsemantics difficulties - mostly derived from the interference with Spanish - that Galician degree students find with their first contact with the Italian language, and, furthermore we will highlight common aspects of the Galician and Italian languages that facilitate the acquisition of Italian using Galician as interlanguage.
\end{abstract}

Key Words: Italian and Galician; Italian and Spanish; contrastive grammar: linguistic competence: Italian as a foreign language; interlanguage 


\section{INTRODUCIÓN}

Un dos principais acertos da reforma educativa introducida pola Declaración de Boloña ten sido focar a atención na avaliación para a aprendizaxe -orientada ao desenvolvemento de competencias por medio da realización de tarefas concretas relacionadas co mundo profesional-e, consecuentemente, reducir o espazo dedicado á avaliación da aprendizaxe, baseada na mera adquisición e repetición de contidos. Así, en cada nivel de aprendizaxe (de A1 a C2) o/a aprendente debe centrar os seus esforzos na execución de actividades prácticas ligadas a competencias como a comprensión oral e escrita, a produción e a interacción orais e a produción escrita, o que provoca que, na maior parte dos casos, a abordaxe teórica da gramática fique relegada a un segundo plano.

Esta mudanza de perspectiva no ensino-aprendizaxe exixe ter en conta as destrezas do alumnado en cada unha das competencias para que o profesorado acompañe mellor o proceso de adquisición dunha nova lingua. A análise das competencias relacionadas cos coñecementos morfosintáctico e léxico-semántico do italiano do estudantado universitario galego, realizada a través de diversos traballos de carácter escrito, revela a existencia de determinados contidos gramaticais de difícil asimilación -e que, se ben non atrapallan a comunicación, restan calidade á escrita-, como por exemplo a formación do plural ou a conxugación verbal -nomeadamente no que atinxe ao pasado próximo-. Non obstante, esta análise mostra tamén como a lingua galega funciona como ponte para aprendizaxe do italiano para un alumnado que ten o galego e o español como linguas instrumentais ${ }^{1}$.

Desta maneira, neste artigo faise un levantamento das cuestións máis relevantes en tarefas relativas á produción escrita nos planos morfosintáctico e léxico-semántico coa finalidade de optimizar o ensino-aprendizaxe desta competencia na lingua italiana no ámbito universitario galego. Recóllense exemplos de usos incorrectos de determinadas categorías gramaticais (principalmente substantivo, pronome clítico, posesivo, verbo e preposición) e estruturas sintácticas e mais de falsos amigos; e, en paralelo, hai casos en que o alumnado de Galiza, por mor da proximidade entre o galego e o italiano, asimila con facilidade tanto certas estruturas morfosintácticas simples como o léxico correspondente aos niveis A1 e A2 do Quadro comune europeo di riferimento per le lingue (QCERL). Por outra parte, convén sinalarmos que neste traballo, non se atende a aspectos de tipo normativo e/ou estilístico, xa que nocións deste teor non se aprecian en niveis básicos de aprendizaxe lingüística como son o A1 e o A2.

En síntese, sistematizamos os contidos gramaticais que suscitan innumerábeis dúbidas no estudantado e tamén aqueles que este xa ten asimilados grazas ao seu coñecemento da lingua de Galiza co obxectivo de atinxirmos maior calidade, eficacia e axilidade no ensino morfosintáctico e lexical do idioma italiano no seo da universidade galega.

\footnotetext{
${ }^{1}$ Para os estudos sobre a interlingua italiano-español, véxanse, entre outros, as contribucións de Calvi (1995, 2004), Ceruti, (2009), Zurlo (2009), De Benedetti (2010), Della Putta (2011, 2015), Bailini (2016).
} 


\section{METODOLOXÍA}

O corpus deste artigo está conformado polos traballos de produción escrita (actividades de tipo estrutural, resumos a partir de textos escritos e redaccións) realizados desde o curso 2010-2011 até o curso 2018-2019 inclusive polo alumnado galego das materias de Idioma Moderno 1: Italiano e Idioma Moderno 2: Italiano, que forman parte do plan de estudos dos graos impartidos na Facultade de Filoloxía da Universidade da Coruña $^{2}$. Estas materias, de carácter cuadrimestral, correspóndense cos niveis A1 e A2 do QCERL e teñen unha dedicación de 6 e 4,5 créditos $^{3}$, respectivamente.

Neste corpus considéranse unicamente os traballos elaborados por estudantes nacidos en Galiza, independentemente de se teñen como lingua inicial o galego ${ }^{4}$ ou o español, e exclúense os do alumnado de orixe non galega.

Ao longo do apartado 3 recóllense os erros morfosintácticos e léxico-semánticos cometidos de maneira recorrente polo estudantado e obsérvanse casos en que non se producen conflitos que adoitan darse en alumnado non galego. A seguir, examináronse estes fenómenos en confronto con varias gramáticas sincrónicas descritivas do italiano (Renzi, 1991; Adorno, 2003), do galego (Freixeiro Mato, 1999 e 2000; López Viñas, Lourenço Módia e Moreda Leirado, 2011) e do español (Real Academia Española, 2010), así como con dicionarios dos tres idiomas.

Por último, no apartado 4 achégase unha reflexión que busca identificar as dificultades reais do alumnado galego nas materias iniciais de italiano como LE coa finalidade de mellorar a súa competencia escrita en italiano a nivel morfosintáctico e léxico-semántico.

\section{A FORMACIÓN DO CORPUS}

\subsection{Nivel morfosintáctico}

O obxectivo deste parágrafo, e dos seguintes, é procedermos á redacción dun corpus comentado en que recollemos algúns dos erros e dos usos impropios máis frecuentes encontrados en exercicios de produción escrita. A maior parte dos aspectos que observamos no material consultado atinxe, fundamentalmente, ao número dos substantivos, a aspectos da conxugación verbal, á colocación dos pronomes clíticos e, en xeral, ás construcións sintácticas.

Observamos, entón, os seguintes exemplos organizados segundo a tipoloxía gramatical encontrados nos traballos de produción escrita.

\footnotetext{
${ }^{2} \mathrm{Na}$ Facultade de Filoloxía da Universidade da Coruña impártense seis graos: Grao en Inglés, Grao en Galego e Portugués, Grao en Español, Dobre Grao en Inglés / Español, Dobre Grao en Inglés / Galego e Portugués e Dobre Grao en Español / Galego e Portugués.

${ }^{3}$ Idioma Moderno: Italiano 1 consta de 44,5 horas presenciais (aproximadamente, 39,5 reais, pois o resto de horas está dedicado á realización de exames) e Idioma Moderno: Italiano 2, de 36 h (que se corresponden con 31,5 na realidade). Para coñecer a planificación destas materias, consúltese a páxina web http://cort.as/Hi2S.

${ }^{4}$ Para achegarse ao uso e ao coñecemento da lingua galega por parte da mocidade, véxase Real Academia Galega (2018).
} 
En relación ao achegamento ao substantivo, o xénero non presenta grandes dificultades para o estudantado, visto que moitos vocábulos italianos que conforman o léxico básico teñen o mesmo xénero que en galego; así, nos traballos do noso alumnado case non se detectan erros na asignación do xénero en palabras como l'acne, il diadema, la dose, il latte, il legume, il massacro, il miele, la pelle, il sale, il sangue, il segnale, la sindrome ou la vertigine, entre outras. Ademais, o italiano partilla o xénero co galego nalgúns termos que comezan por $<a>$ tónico (l'arte, l'aquila, l'acqua, l'anima, etc.) e en moitos termos acabados en <-si> (l'analisi, la crisi, l'enfasi, la sclerosi, la tesi...) e en te (la tonsillite, l'appendicite, l'artrite, la bronchite, l'epatite...), o que facilita o estudo sistematizado de gran parte do léxico.

Os principais problemas danse en relación ao número do substantivo; o erro máis repetido dáse nos substantivos masculinos terminados en $<_{-} o>$ que fan o plural en $<_{-i}>$, pois tanto en galego como en español o plural destes substantivos constrúese engadindo o morfema $<-s>$.

*figlii en lugar de figli.

*i occhio en lugar de gli occhi.

* da piccolos en lugar de da piccoli.

Por outro lado, debido a que o alumnado galego ten dificultades para recoñecer como estranxeirismos certos substantivos xa moi inseridos no léxico galego e español, é frecuente encontrarmos nos traballos de aula palabras estranxeiras con morfema de plural.

*bars por bar.

* computers por computer.

* films por film.

*pubs por pub.

*yogurts por yogurt.

Canto ao adxectivo, un erro recorrente é o uso de vecchio/a no interior dunha estrutura comparativa, pois en galego vello/a fai referencia á idade ${ }^{5}$ de seres animados e inanimados mentres que grande e maior (en italiano 'grande' e 'maggiore', respectivamente) aluden fundamentalmente ao tamaño.

* Ho una cugina che è più vecchia di me (en galego, Teño unha curmá que é máis vella ca min) en lugar de Ho una cugina che è più grande di me.

* Mio fratello è più vecchio di me (en galego, O meu irmán é máis vello ca min) en lugar de Mio fratello è più grande di me.

Por outra parte, sorprende o uso constante de meglio no canto de migliore, pois en galego a única forma posíbel de comparativo de superioridade para o adxectivo bo/boa (en italiano, buono/a) é mellor; esperariamos, por tanto, que o alumnado empregase antes -aínda que erradamente- migliore do que meglio.

\footnotetext{
${ }^{5}$ A primeira acepción que ten este adxectivo no Dicionario da Real Academia Galega é "[Ser vivo] que ten moita idade con respecto á duración normal da súa vida" (Real Academia Galega, 2013).
} 
* Il mio meglio amico si chiama Mario (en galego, O meu mellor amigo chámase Mario) en lugar de Il mio migliore amico si chiama Mario.

* Mia madre fa la meglio tortilla del mondo (en galego, A miña nai fai a mellor tortilla do mundo) en lugar de Mia madre fa la migliore tortilla del mondo.

A respecto da conxugación verbal, unha das maiores dificultades que enfrenta o alumnado galegofalante é a utilización dos verbos essere e stare; en galego e en español ser emprégase para expresar condición (invariábel) e estar indica estado (variábel), da mesma maneira que en español, mentres que en italiano esta distinción non se manifesta no rexistro formal, xa que essere funciona tanto para condición como para estado.

*Io sto molto orgogliosa della mia famiglia en lugar de Io sono molto orgogliosa della mia famiglia.

* Oggi sto felice en lugar de Oggi sono felice.

Talvez a incorrección máis frecuente na conxugación dos verbos italianos sexa a que se produce na P1 do presente do Indicativo de fare. Mesmo en Idioma Moderno 2: Italiano, o galeguismo fago substitúe a palabra faccio na maior parte dos traballos do alumnado.

*Fago i compiti il pomeriggio en lugar de Faccio i compiti il pomeriggio.

*Tutti i giorni fago un po' di sport en lugar de Tutti i giorni faccio un po' di sport.

Outras das dificultades omnipresentes no tocante ao paradigma verbal é a que se dá na adquisición do passato prossimo. Obsérvase nos traballos do noso alumnado o uso constante de avere en vez de essere no passato prossimo, principalmente con verbos de movemento - un calco da estrutura do pretérito perfecto composto do Indicativo español, que se constrúe co auxiliar haber-; por outra parte, en galego non existen os tempos compostos e no canto do passato prossimo acostuma utilizarse o pretérito do Indicativo, mais tamén é común empregar os tempos compostos co auxiliar haber por españolismo.

*Hanno venuto por Sono venuti (en galego, Chegaron; en español, Han llegado).

*Hanno uscito por Sono usciti (en galego, Sairon; en español, Han salido).

Tamén se utiliza inadecuadamente avere en vez de essere cando o verbo é reflexivo ou recíproco.

* Si hanno sposato por Si sono sposati.

* Mi ho fatto la doccia por Mi sono fatto la doccia.

En relación a este fenómeno, é bastante habitual unha selección errada da persoa gramatical.

* Lei non hanno partito por Lei non è partita.

* Noi siete visto por Noi abbiamo visto.

Alén diso, repítense con asiduidade as incorreccións na formación do participio, a maior parte das veces por interferencia co galego e co español, mesmo en casos en que 
non hai unha equivalencia contextual exacta entre a forma italiana e a galega ou española que o estudantado asocia a esta.

* Quando è arrivato a casa gli ho offrito un caffè por Quando è arrivato a casa gli ho offerto un caffè (en galego, Cando chegou a casa ofreceulle un café; en español, Cuando llegó a casa le ofreció un café).

Neste exemplo é clara a asociación formal entre offrire e ofrecer ('por [algo] a disposición de alguén', Real Academia Galega 2013).

As estruturas italianas c'è e ci sono tamén son obxecto de innumerábeis confusións por parte dos / das estudantes; por interferencia co galego e co español, estes/as adoitan empregar o verbo avere cando este fai referencia a un axente indeterminado e utilizan essere cando o axente é indeterminado.

* Ho molti assaggi por Ci sono molti assaggi.

* È una casa por C'è una casa.

Un outro aspecto que chama a atención é a utilización do verbo avere como auxiliar nunha perífrase modal obrigativa; tanto en galego como en español existe a perífrase verbal deber+infinitivo (equivalente á italiana dovere + infinito), mais, como pertence a un rexistro máis formal, o alumnado opta por haber + que + infinitivo (inexistente en italiano), de uso máis estendido.

* Hanno che deciderlo por Devono deciderlo.

* Avete che apparecchiare por Dovete apparecchiare.

Un caso singular é a transposición ao italiano dunha interferencia do español que se produce moi habitualmente en galego a nivel oral; en italiano o estudantado utiliza o verbo fare no canto da preposición da para se referir ao tempo cronolóxico, xa que en galego se acostuma empregar o verbo facer en vez de haber neste tipo de expresións.

* La commedia è iniziata fa mezz'ora por La commedia è iniziata da mezz'ora.

* A comedia comezou fai media hora (por interferencia co español La comedia empezó hace media hora) por A comedia comezou hai media hora.

Tamén se rexistran numerosos casos de confusión na rexencia preposicional do verbo, nomeadamente de verbos de movemento.

* Sono andato al palestra por Sono andato in palestra.

* Siamo entrati per la porta rossa (en galego, Entramos pola porta vermella) por Siamo entrati dalla porta rossa.

* Siamo usciti del cinema alle 21:00 (en galego, Saímos do cinema ás 21:00 h) por Siamo usciti dal cinema alle 21:00.

*Vengo di Galizia (en galego, Veño de Galiza) por Vengo dalla Galizia.

Porén, tamén se dan casos en que hai diferenzas na rexencia de verbos con valores semánticos moi diversos. 
*Ho pensato in quello che mi hai detto (en galego, Pensei no que me dixeches) en lugar de Ho pensato a quello che mi hai detto.

* La cucina profumava a pizza (en galego, A cociña ulía a pizza) en lugar de La cucina profumava di pizza.

Por veces, o problema parte de que en italiano non se emprega preposición con certos verbos, mentres que en galego e en español si.

* Da bambino sognavo con i mostri (en galego, De neno soñaba cos monstros) en lugar de Da bambino sognavo i mostri.

* Ieri sono uscito di festa con i miei amici (en galego, Onte saín de festa cos meus amigos) en lugar de Ieri sono uscito con i miei amici.

En relación ao pronome, detéctanse vacilacións nos usos e nas formas dos pronomes persoais tónico e átono, do posesivo, do identificador e mais do numeral cardinal. Se cadra, no que atinxe ao pronome persoal tónico, o erro máis frecuente sexa o uso de ela, a forma feminina singular de P3 en galego.

*Ela è piccola (en galego, Ela é nova) por Lei è piccola.

* Ela è mia sorella (en galego, Ela é a miña irmá) por Lei è mia sorella.

Resulta rechamante que mesmo o alumnado español-falante substitúa lei pola forma galega ela e non pola case idéntica correspondente en español, ella, o que reafirma a idea de que este grupo de estudantes recorre ao galego como interlingua para chegar ao italiano.

No que se refire ao pronome clítico, a confusión entre la e le é recorrente e posiblemente se deba a que en galego e en español o pronome persoal átono de complemento directo en feminino acaba en $\langle a>$.

* La telefonerai (a lei) por Le telefonerai (Telefonareina, en galego; La telefonearé, en español).

* La chiederai (a lei) por Le chiederai (Preguntareille, en galego; Le preguntaré, en español).

Canto ao posesivo, un dos erros máis reiterados é a presenza do artigo antes desta categoría cando fai referencia a nomes de familia, erro que parece explicarse polo uso peculiar do artigo perante posesivo en italiano. En galego contémplase a posibilidade de empregar artigo diante de posesivo para introducir nomes de parentesco próximo (Freixeiro Mato, 2000: 274-280; López Viñas, Lourenço Módia e Moreda Leirado, 2011: 265), mentres que en español nunca se utiliza o artigo antes de posesivo (RAE, 2010: 343-353); desta maneira, son máis numerosos os casos en que o defecto se dá pola presenza inadecuada do artigo que pola súa ausencia.

* La mia madre è infermiera por Mia madre è infermiera (en galego, Miña nai é enfermeira ou A miña nai é enfermeira; en español, Mi madre es enfermera).

* Suei nipoti vivono in Francia por I suoi nipoti vivono in Francia (en galego, Os seus sobriños / netos viven en Francia; en español, Sus sobrinos / nietos viven en Francia). 
A respecto do artigo, sorprende que, a pesar de que o $C D$ en español leva preposición $a$ perante seres animados, a maior parte do alumnado non erra na utilización desta categoría gramatical, pois en galego non se usa $a$ neste contexto (salvo en casos excepcionais).

Il cacciatore decide di uccidere il cervo (en galego, $O$ cazador decide matar o cervo; en español, El cazador decide matar al ciervo).

Ho visto un ragazzo (en galego, Vin un rapaz; en español, Vi a un chico).

No tocante ao pronome identificador invariábel qualunque, resulta frecuente a súa utilización seguido dunha oración de relativo con verbo en subxuntivo, por interferencia co galego e co español.

* Mangiare qualcosa che voglia por Mangiare qualunque cosa (en galego, Comer calquera cousa que queira, e Comer cualquier cosa que quiera en español).

* Farei qualcosa per aiutarlo por Farei qualunque cosa per aiutarlo (en galego, Faría calquera cousa por axudalo e Haría cualquier cosa por ayudarlo en español).

Nas oracións que conteñen numerais cardinais é frecuente a omisión do substantivo, tal e como acontece en galego e español.

*_Quanti anni hai? / - Ho trentacinque (en galego, —Cantos anos tes? / - Teño trinta e cinco: en español, —¿Cuántos años tienes? / - Tengo treinta y cinco.) en lugar de - Quanti anni hai? / - Ho trentacinque anni.

A respecto da preposición, as maiores dúbidas proveñen do uso de $d a$ cando indica procedencia. Por exemplo, o estudantado emprega esta forma para introducir tanto un topónimo de cidade (correcto) como un topónimo de país (incorrecto).

* Il caffè viene da Yemen por Il caffè viene dallo Yemen (en galego, O café vén do Iemen).

*Freddie Mercury viene da Tanzania por Freddie Mercury viene dalla Tanzania (en galego, Freddie Mercury vén de Tanzania).

Tamén se rexistra a confusión entre $d a$ e per debido á interferencia co galego e co español.

* La mela è mangiata per me por La mela è mangiata da me (en galego, A mazá é comida por min; en español, La manzana es comida por mi).

* La mia famiglia sta composta per mia madre, mio padre e io por La mia famiglia è composta da mia madre, mio padre ed io (en galego, A miña familia está composta por miña nai, meu pai e eu; Mi familia está compuesta por mi madre, mi padre y yo).

Por outro lado, tamén se dan casos de uso incorrecto da preposición di perante topónimos, que asentan en construcións galegas e españolas.

*Sono di Galizia en lugar de Sono gallego (en galego, Son de Galiza; en español, Soy de Galicia).

* Siamo di Andalusia en lugar de Siamo andalusi (en galego e en español, Somos de Andalucía). 
Tamén en relación a esta preposición, o estudantado adoita empregar di precedida do verbo nascere, talvez por non apreciar as diferenzas existentes entre as nocións lugar de nacemento e procedencia.

* Sono nata di Paesi Bassi por Sono nata nei Paesi Bassi.

* Mio fratello è nato di Stati Uniti por Mio fratello è nato negli Stati Uniti.

Por outra parte, é case sistemática a confusión no uso da preposición tra / fra, en oracións que indican tempo cronolóxico. Así, constátase habitualmente o emprego de in por interferencia coa preposición galega e española en.

*Ci vediamo in mezz'ora en lugar de Ci vediamo tra / fra mezz'ora (en galego, Vémonos en media hora; en español, Nos vemos en media hora).

* Mi alzo in cinque minuti en lugar de Mi alzo tra / fra cinque minuti (en galego, Érgome en cinco minutos; en español, Me levanto en cinco minutos).

E, por último, no relativo ás conxuncións, nos traballos analizados encontramos reiteradamente o galeguismo coma en lugar da conxunción comparativa come.

*Lavora coma professore por Lavora come professore (en galego, Traballa como profesor).

*Studia coma un matto por Studia come un matto (en galego, Estuda como un tolo).

Así, podemos testemuñar máis unha vez que, para o noso estudantado, o galego funciona como unha interlingua na aprendizaxe do italiano, pois nos traballos substitúe come por coma tamén en casos en que en galego se pode utilizar indistintamente comaconxunción exclusivamente galega- e como -conxunción galega e española-.

\subsection{Nivel léxico-semántico}

Do punto de vista léxico-semántico, as disfuncións máis recorrentes son o falso amigo (Enciclopedia Treccani, 2010) ${ }^{6}$ e o calco (Enciclopedia Treccani, 2012) ${ }^{7}$.

*Mio fratello studia all'instituto (en galego, O meu irmán estuda no instituto; en español, Mi hermano estudia en el instituto) en lugar de Mio fratello studia alla scuola superiore.

* Questa carne è mala (en galego, Esta carne é mala; en español, Esta carne es mala) en lugar de Questa carne è cattiva.

Neste último caso, ademais, cattiva rexéitase porque interfire coa palabra galega cativa, que ten como significado primario 'pequena' ${ }^{8}$.

Son varios os casos en que unha palabra en galego presenta varios significados, mentres que esa mesma palabra en italiano só se utiliza con unha destas acepcións. Por exemplo, o vocábulo matrimonio (idéntico canto ao significante nas dúas linguas) en

\footnotetext{
${ }^{6}$ Revísese http://cort.as/-Hi5p.

${ }^{7}$ Consúltese a páxina http://cort.as/-Hi5L.

${ }^{8} \mathrm{O}$ adxectivo galego cativo/a tamén ten a acepción de "ruín, mao/má", mais é posíbel que unicamente sexa de uso común no alumnado galegofalante.
} 
galego e en español úsase como 'casamento' e como 'dúas persoas casadas'; no entanto, en italiano este vocábulo só alude ao acto de casar.

* Il mio papà e la mia mammà sono in matrimonio da venti anni por Il mio papà e la mia mamma sono sposati da venti anni.

Un exemplo semellante encontrámono no termo commercio, que en galego e en español se aplica tanto a un local comercial ${ }^{9}$ como ao de acto comerciar, mentres que en italiano só se refire á segunda destas acepcións.

* Mia zia lavora in un commercio por Mia zia lavora in un negozio.

Outro caso similar acontece con cibo, que en italiano se refire unicamente a un produto alimenticio; en galego e en español comida presenta dúas acepcións, a anterior e o xantar.

* La sera faccio il cibo por La sera preparo la cena.

Nos exercicios analizados detéctanse numerosos falsos amigos entre o italiano e mais o galego e español, como, por exemplo burro ('asino'), caldo ('brodo'), lama ('fango'), guardare ('conservare'), imbarazzata ('incinta') e gamba ('gamberetto').

Por veces encontramos falsos amigos que conteñen modificacións de significante procedentes da interferencia co galego. É o caso de padrigno $^{10}$ (interferido pola palabra galega padriño, cuxo significado é (padrino') empregado no canto de patrigno.

* Il mio padrigno si chiama Antonio. Si è sposato con la mia mamma l'anno scorso por Il mio patrigno si chiama Antonio. Si è sposato con la mia mamma l'anno scorso.

Tamén se rexistra algún caso en que o falso amigo só se dá en galego; o alumnado, unha vez máis, usa o galego como interlingua e erra na escolla lexical. Isto acontece, por exemplo, con strada / estrada; en italiano, strada significa 'rúa', entendida como lugar por onde transitan tanto persoas como vehículos; no entanto, estrada fai referencia unicamente á vía pola cal se moven estes últimos.

Il camion bloccava il traffico per la strada (en galego, O camión bloqueaba o tránsito na estrada).

Chama a atención a confusión entre vedere e guardare, que sorprendentemente non se xustifica por interferencia, visto que tanto en galego como en español se corresponden con ver (galego e español) e ollar (galego)/mirar (galego e español) respectivamente.

* Non so dove è perché è da molto tempo che non lo guardo por Non so dove è perché è da molto tempo che non lo vedo.

\footnotetext{
${ }^{9}$ Esta interferencia resulta rechamante en persoas tan novas como os/as nosos/as alumnos/as, pois o uso de comercio en galego e en español co significado de 'local comercial' adoita darse en persoas de máis idade. ${ }^{10}$ A palabra padrigno en italiano ten a mesma acepción que patrigno mais emprégase con menor frecuencia.
} 
Tamén no plano léxico se constata o emprego de anglicismos no canto de vocábulos italianos asentados; é o caso, por exemplo, de smartphone (en lugar de telefonino), staff (en lugar de gruppo) ou boss (en lugar de capo) etc. Sexa como for, no cómputo xeral dos erros lingüísticos compilados neste traballo este feito non resulta tan rechamante debido á existencia de certa permisividade do italiano no uso destes estranxeirismos, permisividade reforzada polas escollas léxicas estranxeirizantes dalgúns manuais de italiano como LE.

Finalmente, tamén hai que apuntar que parte das dificultades que atinxen ao plano léxico-semántico refírese, fundamentalmente, ás interferencias do italiano co galego e co español. Dado que unha boa parte do estudantado se dedica ao estudo doutras linguas estranxeiras ademais do italiano, pode pasar que, nalgúns casos, haxa unha dupla interferencia co inglés ou co francés, como se ilustra nos seguintes exemplos:

* Ho delle belle memorie en lugar de Ho dei bei ricordi.

* Ho letto un magazine en lugar de Ho letto una rivista.

\section{CONCLUSIÓNS}

A análise dos traballos de produción escrita efectuados polo alumnado das materias Idioma Moderno 1: Italiano e Idioma Moderno 2: Italiano impartidas nos Graos de Español, Galego e Portugués e Inglés da Universidade da Coruña entre os cursos 20102011 e 2018-2019 revela unha serie de aspectos conceptuais da lingua italiana que cómpre revisarmos, dado que provocan con frecuencia dúbidas e erros.

Primeiramente, rexístranse algúns erros en relación á formación do plural dos substantivos (sobre todo nos terminados en $-o$ e nos estranxeirismos) e ao uso de adxectivos como vecchio/a e meglio. En segundo lugar, obsérvase que o groso das disfuncións se localiza na conxugación verbal; así, é recorrente a confusión entre essere e stare, essere e avere (nomeadamente no pasado próximo e con verbo reflexivo) e mais c'è e ci sono, ben como os erros na conxugación de fare, na formación do participio e da perífrase modal obrigativa e na rexencia preposicional de moitos verbos. Tamén se aprecian dificultades a respecto do pronome, mais en casos puntuais que se reducen á confusión dos clíticos la / le e a certos usos e formas dos pronomes tónico e átono, ao posesivo (principalmente ao asociado con nomes de familia), ao identificador invariábel qualunque e ao numeral cardinal. Alén disto, verifícanse tamén algúns problemas na utilización de certas preposicións; é habitual a presenza errada de $d a$ indicando procedencia e de di perante topónimos ou despois de nascere, así como a confusión de da / per, principalmente para indicar tempo cronolóxico, e de tra / fra. Por último, e xa no ámbito léxico-semántico, os erros gardan relación fundamentalmente co emprego de falsos amigos, calcos e anglicismos prescindíbeis.

Non obstante, a análise do corpus revela tamén que o galego actúa como ponte no proceso de adquisición do italiano por parte do noso alumnado; nalgúns casos os / as estudantes galegos -en virtude das evidentes semellanzas entre os dous idiomas- non erran nas construcións morfosintácticas (flexión de xénero en termos que comezan por $<a>$ tónico ou que acaban en $-s i$; construción de CD sen $a$ perante seres animados, por 
exemplo) nin nas escollas léxicas en casos en que alumnos/as doutras procedencias si o fan, ou ben recorren ao galeguismo (fago, ela etc.), evidenciando a utilización do galego como interlingua.

A identificación e análise dos problemas e das vantaxes que acabamos de sinalar resulta fundamental para que o profesorado de italiano como lingua estranxeira en Galiza poida confeccionar programacións máis eficaces e mellor adaptadas ás necesidades do seu estudantado, o que, alén de facilitar o labor docente, redundaría nunha mellora substancial no rendemento académico dos / das alumnos/as.

Por outra parte, e á vista de que existen cuestións gramaticais que o noso estudantado asimila mellor que o de fóra de Galiza, conviría a organización de cursos de actualización para o profesorado de italiano como lingua estranxeira (LE) que inclúan seminarios de aproximación á lingua galega para os docentes nativos de italiano, co obxectivo de apostarmos por unha formación máis especializada dos cadros docentes.

Alén disto, tamén sería aconsellábel a publicación dun manual de italiano como lingua estranxeira orientado a un público galegofalante ou, simplemente, galego, visto que a lingua propia de Galiza actúa, como puidemos comprobar ao longo do traballo, como unha interlingua tanto para o alumnado galegofalante como para o españolfalante. Sen dúbida, o desenvolvemento de accións como estas traduciríase nunha sensíbel mellora no ensino-aprendizaxe do alumnado do sistema universitario galego.

\section{REFERENCIAS BIBLIOGRÁFICAS}

Bailini, S. (2016). La interlengua de lenguas afines. El español de los italianos, el italiano de los españoles. Milano: LED.

Calvi, M. V. (1995). Didattica di lingue affini: spagnolo e italiano. Milano: Guerini Scientifica.

Calvi, M. V. (2004). Apprendimento del lessico di lingue affini. Cuadernos de Filología italiana, 11, 61-71.

Ceruti, E. (2009). Linguistica contrastiva e didattica di lingue affini: l'insegnamento dell'italiano ad un pubblico ispanofono. Romanitas, lenguas y literaturas romances, 4 (1), 1-14.

Consiglio d'Europa. (2002). Quadro comune europeo di riferimento per le lingue: apprendimento, insegnamento, valutazione. Firenze: La Nuova Italia / Oxford.

Dardano, M. e Trifone, P. (2010). La nuova grammatica della lingua italiana. Bologna: Zanichelli.

De Benedetti A. (2006). Liscio come l'aceite. Errori di interferenza (e non) nell'apprendimento dell'italiano L2 in parlanti ispanofoni. En Saperi per insegnare. Formazione di insegnanti di italiano LS/L2 fra scuola e università, F. Bosc, C. Marello e S. Mosca (eds.), 205-217. Torino: Loescher.

Della Putta, P. (2011). "Ho conosciuto a Jorge l'anno scorso": proposte glottodidattiche e riflessioni teoriche su un'interferenza sintattica nelle interlingue di ispanofoni. Italiano LinguaDue, 3(2), 79-93.

Della Putta, P. A. (2015). “Hai visto a tuo amico?" L'effetto dell'input su due tratti caratteristici dell'interlingua italiana degli ispanofoni. En Congresso AItLA 2014, 231-254. Milano: Officinaventuno. 
Freixeiro Mato, X. R. (1999). Gramática da lingua galega, III. Semántica. Vigo: A Nosa Terra.

Freixeiro Mato, X. R. (2000). Gramática da lingua galega, II. Morfosintaxe Vigo: A Nosa Terra.

González, I. (dir.) (2000). Diccionario Italiano-Galego, Centro de Investigacións en Humanidades Ramón Piñeiro, Xunta de Galicia, Santiago de Compostela.

López Viñas, X., Lourenço Módia, C. e Moreda Leirado, M. (2011). Gramática práctica da lingua galega. Comunicación e expresión. A Coruña: Baía Edicións.

Real Academia Española (2018). Diccionario de la lengua española. http://dle.rae.es/?w=diccionario.

Real Academia Española (2010). Nueva gramática de la lengua española. Madrid: Espasa Libros.

Real Academia Galega (2013). Dicionario da Real Academia Galega. https://academia.gal/dicionario.

Real Academia Galega (2018). Lingua e sociedade en Galicia. Resumo de resultados 1992-2016.

http://publicacions.academia.gal/index.php/rag/catalog/view/327/328/1053-1

Renzi, L., Salvi, G. e Cardinaletti, A. (eds.) (1991). Grande grammatica italiana di consultazione, I. Bologna: Il Mulino.

Sánchez Palomino, M. D. (2016). As equivalencias na actual lexicografía bilingüe castelán-galego (o dicionario da RAG). En Cantares de amigos. Estudos en homenaxe a Mercedes Brea, E. Corral Díaz, E. Fidalgo Francisco e P. Lorenzo Gradín (eds.), 813-824. Santiago de Compostela: Universidade de Santiago de Compostela.

Sánchez Palomino, M. D. (2019). Criterios en la elaboración del diccionario bilingüe castellano-gallego de la Real Academia Galega. En La investigación en lexicografia hoy: diccionarios bilingües, lingüística y uso del diccionario, C. Calvo Rigual, F. Robles Sabater (eds.), Colección de Anejos de Quaderns de filología. Estudis lingüistics, 49-70. Valencia: Universitat de València.

Zurlo, F. (2009). Fenomeni d'interferenza nell'apprendimento dell'italiano da parte di parlanti spagnolo. Un'indagine a partire da un test a scelta multipla per gli studenti dell'Università Complutense di Madrid, Italiano LinguaDue 1(1), 55-67. 